\title{
Wind Tunnel Measurements of a Multibladed Horizontal-Axis Small Wind Turbine
}

\author{
Heitor Andrade Porto ${ }^{1, *}$ (D), Carlos Fortulan ${ }^{1}$, Arthur José Vieira Porto ${ }^{1}$ (]) \\ 1.Universidade de São Paulo - Escola de Engenharia de São Carlos - São Carlos/SP - Brazil. \\ *Correspondence author: heitoraporto@gmail.com
}

\begin{abstract}
This work experimentally investigates the effects that a different number of blades, three and five, has in the dynamic torque, acceleration, and power performance of a horizontal-axis small wind turbine. It presents the methodology used for calculating the temporal behavior of the aerodynamic torque generated by the blades during their acceleration phase. The tests were performed in an open section wind tunnel of $1.0 \times 0.8 \mathrm{~m}$. The model was produced by additive manufacturing and had two possible assemblies, with three and five blades. An in-line dynamic torque meter acquired the torque and angular speed data, and a National Instruments USB-6009 device processed the signal. The resistive torques were calculated by spindown tests. The tests were executed at a wind speed of $10 \mathrm{~m} \cdot \mathrm{s}^{-1}$. The measurements displayed the five blades assembly having improved performance compared to the three blades: a higher static torque, which resulted in shorter stating time, and a power coefficient $39 \%$ higher.
\end{abstract}

Keywords: Horizontal-axis small wind turbine; Wind tunnel; Starting time; Dynamic torque; Additive manufacturing.

\section{INTRODUCTION}

Small wind turbines (SWTs) are horizontal-axis or vertical-axis devices and, like their large counterparts, are mostly constructed with three blades. Their power potential is characterized by their power coefficient $(C P)$ value, which is the relation between the turbines power output and the power available at the wind. The maximum $C p$ value a wind turbine can achieve is 0.593 and it is denominated as the Betz limit (van Kuik et al. 2015). However, due to several system losses, in real applications, this value will always be below the Betz limit. The $C p$ values are usually presented in a $C P$ vs. tip-speed ratio (TSR) curve, where TSR is the ratio between the blades tip-speed and the wind speed (Tummala et al. 2016).

Small wind turbines projects are not only bounded to energy harvesting. Noise level, security concerns, social impact, and project liability are other factors that determine the success of SWTs (Fields et al. 2016; Scappatici et al. 2016). In addition, proper wind resource assessment and suitable local energy tariffs are essential for a productive operation (Grieser et al. 2015; Mithraratne 2009; Olsen and Preus 2015; Peacock et al. 2008; Sunderland et al. 2016).

Received: Dec. 22, 2020 | Accepted: Sept. 06, 2021

Peer Review History: Single Blind Peer Review.

Section Editor: Rodrigo Palharini

This is an open access article distributed under the terms of the Creative Commons license. 
Large wind turbines are installed in areas that experience extensive wind resource assessment. On the contrary, SWTs are installed given the customer resource assessment and given the customer demand and opportunity, without a proper wind resource assessment, which tends to result in turbulent low-speed areas (Ani et al. 2013; Tummala et al. 2016). These wind characteristics combined to the SWTs low mass moment of inertia causes the turbine performance to rely on the dynamic response, as it will experience several acceleration and deceleration periods (Lubitz 2014, Tang et al. 2013).

This condition presents a challenge for proper estimating the energy output of SWTs on such environments (Sunderland et al. 2013). Turbulent wind also increases the blade design complexity as the loads acting on the blades are intricate to model given the sudden movements that the turbine experiences (Wilson and Clausen 2007).

Small wind turbines are personal use machines, consequently, they must be low-priced, which requires a considerable level of simplicity. As a result, SWTs blades commonly do not present a pitch control mechanism, with the angular speed control being implemented directly through the generator electro-mechanical torque. The lack of a pitch control mechanism causes the blades to face high angles-of-attack and low Reynolds number on starting situations. Because of these aerodynamic characteristics, the starting phase is a significant aspect of SWTs performance and, at the same time, intricate to model (Wright and Wood 2004).

Several works investigated the effects of improving SWTs dynamic response on their power performance (Clifton-Smith and Wood 2007; Sessarego and Wood 2015). It is known that modifications on the blades geometry can improve the dynamic response, but result in a decrease of the maximum Cp value (Pourrajabian et al. 2016; Wood 2004).

The addition of blades will also affect the power performance and the dynamic response of SWTs (Pourrajabian et al. 2014). Duquette and Visser (2003) showed that increasing the number of blades significantly increased the $C p$ values of simulated turbines.

This work experimentally investigates the effects that the addition of two blades in a traditional three-blade design has in the dynamic response and power performance of the turbine. It also presents the methodology used for calculating the temporal behavior of the aerodynamic torque produced by the blades during the turbines starting phase.

All the blades have the same characteristics (chord, twist, and airfoil sections). Therefore, the resultant effects are related solely to the increment on the number of blades. All the model parts were manufactured by additive manufacturing (AM).

The performance improvements provided by a higher number of blades, their relatively low-cost, and the possibility to employ innovative technologies, such as AM, for their manufacturing, present an opportunity for developing higher efficiency multibladed SWTs (Sessarego and Wood 2015).

\section{MATERIAL AND METHODS}

This section includes details of the project and manufacturing of the SWT parts and the methodology of the experiments.

\section{Project and manufacturing}

The model was designed to have two assembly possibilities, with three or five blades, a simple arrangement, and a nose cone to reduce the flow disturbances between the blades root and the hub. The hub, nose cone, and blades were manufactured by AM. An aluminum shaft acted as the central assembly part, connecting the model to the torque meter.

The blades were designed connected to their base as one single structure. Their attachment to the hub was made through two fixing holes in their base. The nose-cone was positioned facing the hub and blades base and was fixed by the shaft (Fig. 1).

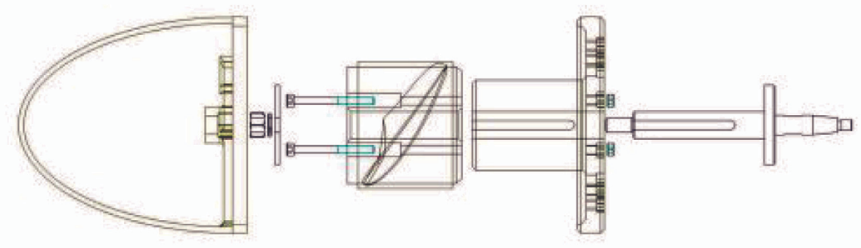

Figure 1. Illustration of the SWT parts assembly. 
The turbine has a diameter of $0.5 \mathrm{~m}$, the inner aerodynamic section is positioned at a radial distance of $0.06 \mathrm{~m}$, and the airfoil composing the blades is the SG6043, a low Reynolds airfoil with 10\% thickness-to-chord ratio.

Figure 2 shows the turbine assembled to the torque meter.

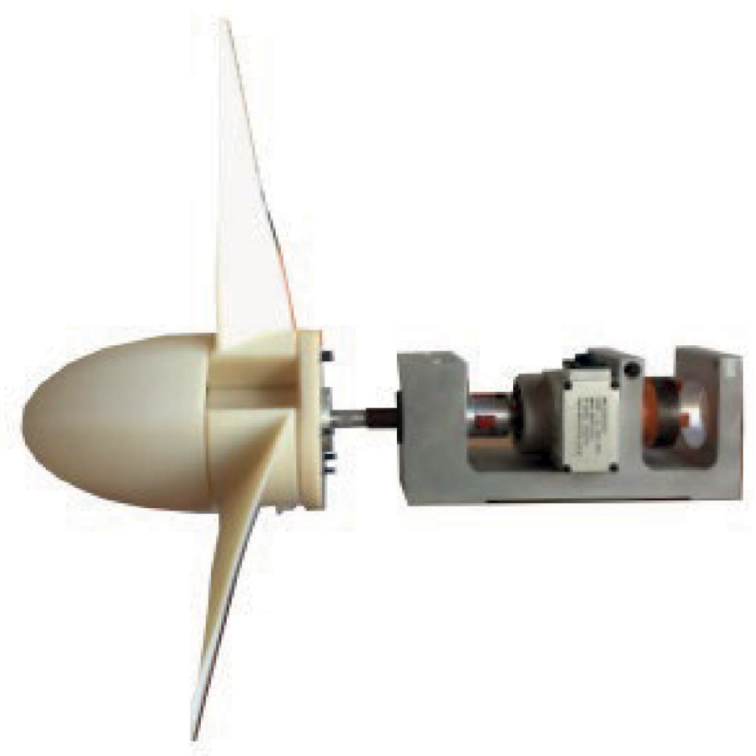

Figure 2. An SWT and torque meter assembly illustration.

The decision to manufacture the parts by AM was part of a work that seeks to evaluate the application of the technology to produce SWT parts. The blades are made of the ABS P430 thermoplastic, produced by Stratasys P430 (Lovo and Fortulan 2016).

Additive manufacturing allowed producing, in single operations, complexes structures and geometries. To mention, the nose-cone and its internal structure, which increases its structural rigidity and permits the assembly of the shaft (Fig. 3); also, the blades, which have high torsion and tapering, combined with the complex airfoil geometry. Additive manufacturing allowed designing the blades base as one single structure, with the fixing holes included (Fig 4). This strategy enables to assemble the complete SWT without further machine tool operations and increases design flexibility, as project changes can be applied on-demand.

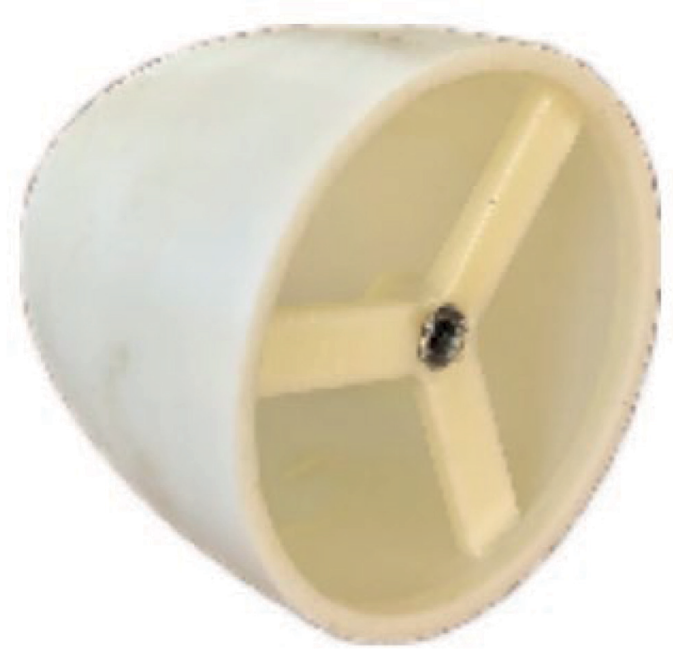

Figure 3. Detail of nose cone internal structure. 


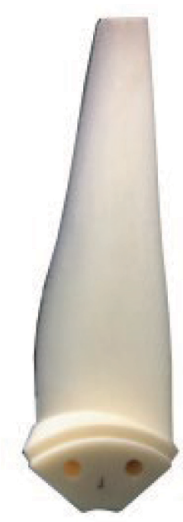

Figure 4. Blade detail, with fixing holes and base produced in a single operation as one part.

\section{Wind tunnel tests methodology}

The experiments proposal was to examine the different dynamic torque, acceleration, and power performance of the three and five blades configurations. For this, a $5 \mathrm{Nm}$ MKDQ torque meter was used (MK Controle e Instrumentação Ltda 2021), it contains a Wheatstone bridge circuit on its rotating frame, a nominal sensitivity of $2.0 \mathrm{mV} \cdot \mathrm{V}^{-1}$, and a zero balance of $\pm 1.0 \%$. The torque meter had an interface with LabView. The signal processing was done by a National Instruments USB-6009 device (National Instruments 2017), the torque meter sent analog signals to the USB-6009 and it converted to a digital output and communicated to the computer having LabView.

On the other end of the torque meter, in opposition to the turbine, an inertia disc was added. The complete system can be characterized as in Fig. 5. Where T is the SWT, D is the inertia disc, M1 and M2 are the outside bearings, MT1 and MT2 are the torque meter internal bearings, and TQ the torque meter. From the figure one can notice that to calculate the aerodynamic torque of the turbine, it is necessary to transfer the value measured at the torque meter to the turbine, considering the resistive torques of the system.

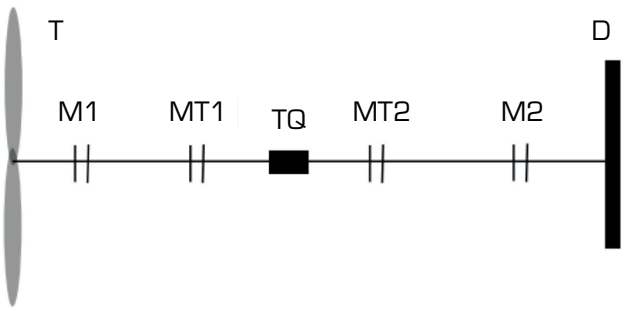

Figure 5. Complete system illustration.

The equation of the system is:

$$
\tau_{T}=\tau_{M 1}+\tau_{M T 1}+\tau_{M T 2}+\tau_{M 2}+\tau_{D}+\text { Iass } \times \alpha
$$

where $\tau$ stands for torque, Iass the mass-moment of inertia of the assembly, and $\alpha$ the angular acceleration.

The system can be further divided at the torque-meter, resulting in two separate equations (Eqs. 2 and 3):

$$
\begin{aligned}
& \tau_{T Q}=\tau_{T}-\tau_{M 1}-\tau_{M T 1}-I 1 \times \alpha \\
& \tau_{T Q}=\tau_{M T 2}+\tau_{M 2}+\tau_{D}+I 2 \times \alpha
\end{aligned}
$$

where, $I 1$ and $I 2$ refer to the mass-moment of inertia of, respectively, the front (turbine) and rear (disc) sections. The torque at the bearings and disc are resistive torques due to mechanical and aerodynamic friction, respectively. 
To calculate the value of $\tau_{\mathrm{T}}$ one must also calculate the value of the resistive torques, the inertia, and the angular acceleration. The signal from the torque-meter had a high level of noise, so it was filtered by a 3rd order low-pass Butterworth digital filter.

The angular acceleration was calculated from the torque signal. Given intrinsic characteristics of the torque meter, it generates an oscillatory signal, which, with the proper sampling rate, can be converted to angular speed data.

The frequency $(f)$ of the oscillatory signal varies with the angular speed $(\omega)$ as $\omega=2 \pi f$. The limit angular speed estimated for the tests was $1500 \mathrm{rpm}$, which results in a frequency of $25 \mathrm{~Hz}$. Therefore, the Nyquist frequency was $50 \mathrm{~Hz}$ and the sampling rate defined as $100 \mathrm{~Hz}$.

Calculating a spectrogram of the torque signal allows to identify the angular speed curve (Fig. 6).

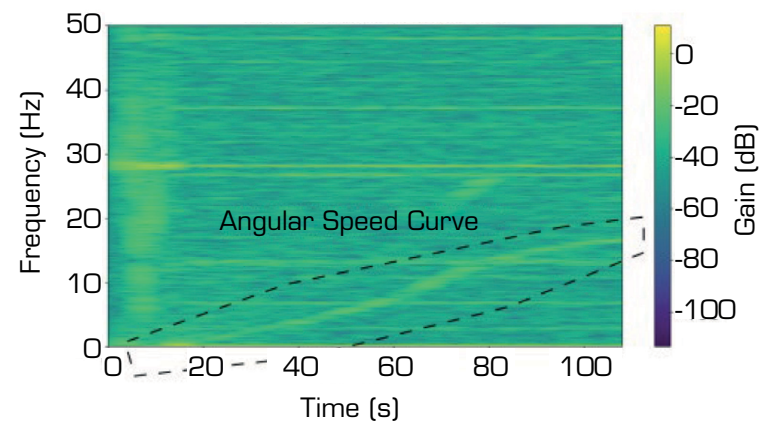

Figure 6. Spectrogram of the torque signal. The angular speed curve is highlighted.

A proper definition of the spectrogram parameters, combined with computer vision techniques, allow for automatic calculation of the angular speed curve. The application of this methodology resulted in a resolution for the angular speed values of $1.7 \mathrm{rad} \cdot \mathrm{s}^{-1}$.

The resistive torque values were calculated by spin-down tests, in which the system was put to spin, and the deceleration curve was measured by the means mentioned above. The angular acceleration curve was calculated by differentiating the angular speed curve. And so, the resistive torque was calculated taking into consideration the inertia of the analyzed components by the relation $\tau=\alpha \cdot l$. A second-order polynomial relating torque and angular speed was defined for the combined effects of all the resistive components $\left(\tau_{\mathrm{D}}, \tau_{\mathrm{M} 1}, \tau_{\mathrm{M} 2}, \tau_{\mathrm{MT} 1}, \tau_{\mathrm{MT} 2}\right)$ and also for the combined effects of only back resistive components $\left(\tau_{\mathrm{D}}, \tau_{\mathrm{M} 2}, \tau_{\mathrm{MT} 2}\right)$.

Three different inertia discs were studied. The one that, during the spin-down tests, had the maximum angular speed closest to the calculated for the wind tunnel tests was selected. During the spin-down tests, the selected disc reached a value of about $1000 \mathrm{rpm}$. Its mass moment of inertia of the was $I_{\mathrm{D}}=0.019 \mathrm{kgm}^{2}$.

The mass moment of inertia values $I 1$ and $I 2$ are dominated by the turbine and disc values, respectively. Their values are $I 1_{3}=0.004 \mathrm{kgm}^{2}$ (for the three blades), $I 1_{5}=0.006 \mathrm{kgm}^{2}$ (for the five blades), and $I 2=0.019 \mathrm{kgm}^{2}$.

Figure 7 shows the complete system assembly.

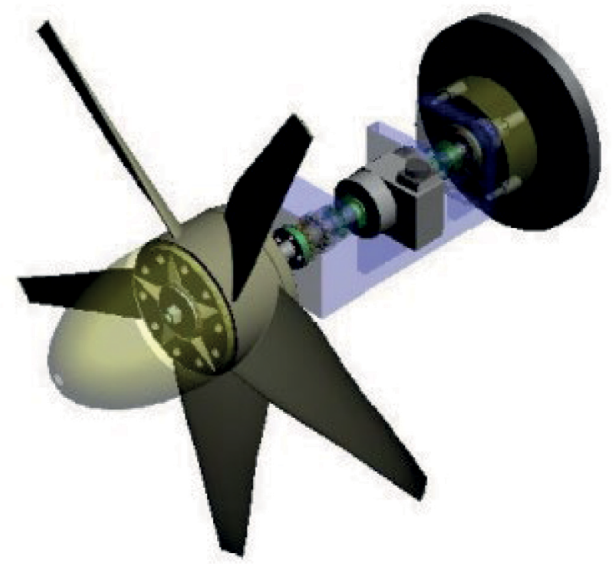

Figure 7. Illustration of the turbine, torque meter, and disc assembly. 
The disc and turbine assembly were balanced using a VIBROCONTROL BMX 900 dynamic balancing machine. The system was mounted in a slender reinforced support structure and positioned on the wind tunnel test section (Fig. 8). The wind tunnel is located at the University of São Paulo in the city of São Carlos and has an open section of $1.0 \times 0.8 \mathrm{~m}$, a maximum wind speed of $32 \mathrm{~m} \cdot \mathrm{s}^{-1}$, maximum motor angular speed of $1175 \mathrm{rpm}$, and maximum motor power of $40 \mathrm{Hp}$.

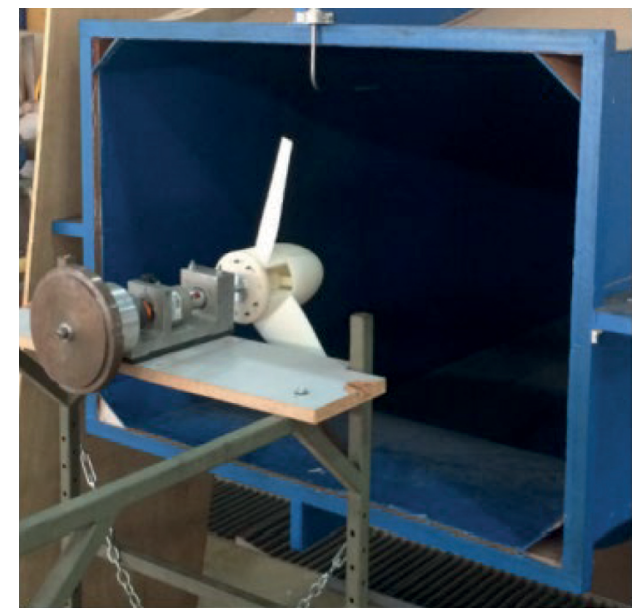

Figure 8. Turbine and support structure positioned at the open section wind tunnel.

The tests were performed at a wind speed of $10 \mathrm{~m} \cdot \mathrm{s}^{-1}$. The system was held still in a fixed predetermined initial position (which was reset for each data acquisition) and allowed to turn at a predetermined time after the flow speed had stabilized. The flow speed was measured by a pitot tube connected to a digital manometer. The torque meter output signal was measured until the system reached zero acceleration. The constant angular speed condition was measured with the use of a phototachometer, and so the duration of the tests could be determined (Fig. 9).

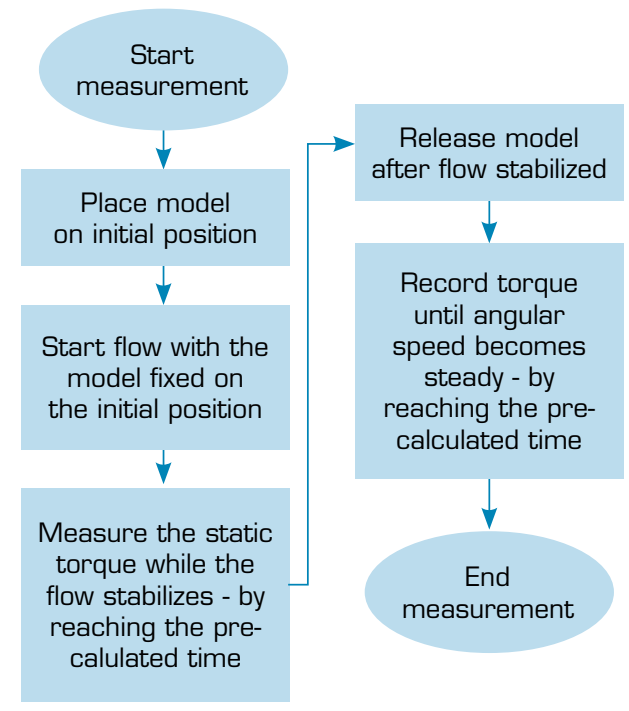

Figure 9. Flowchart of the measurement procedure.

Twenty-five acquisitions were performed for the five blades configuration, five for each blade at the initial position. Twentyfour acquisitions were performed for the three blades configuration, eight for each blade at the initial position.

The average of the measured $\tau_{\mathrm{TQ}}$ and $\alpha$ values were applied in Eq. 2 for the calculation of the aerodynamic torque values. To perform the calculations presented in Eqs. 2 and 3, the torque and angular speed values were resampled to the same timeframe reference. The angular acceleration was calculated by differentiating the angular speed values. 


\section{RESULTS AND DISCUSSION}

The time-series of the average aerodynamic torque and angular speed for the three blades configuration are shown in Fig. 10. The mechanical power produced by the blades was calculated as $P_{b l}=\tau T$, and is shown in Fig. 11 . The $C p$ values were then calculated as $C p=P_{b l} / 0.5 \rho S U^{3}$, where $\rho$ is the air density, $S$ the turbine area and $U$ the flow speed. The $C p$ vs. TSR value for the three blades configuration is shown in Fig. 12, where TSR is the tip-speed-ratio, defined as $\omega \cdot R / U$.

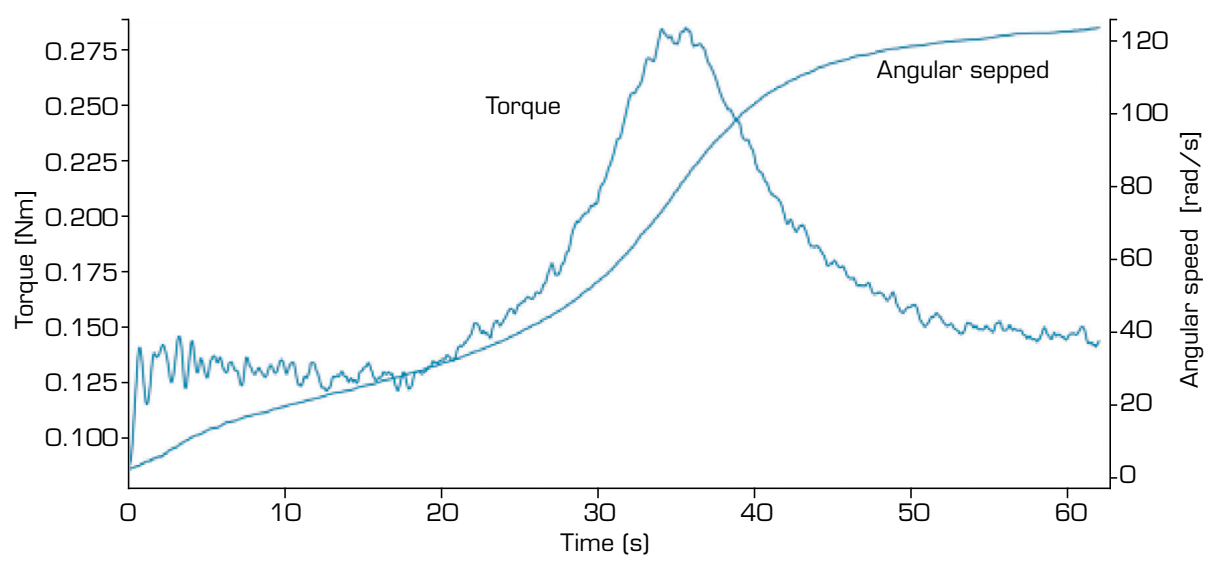

Figure 10. Time-series of the average aerodynamic torque and angular speed for the three blades.

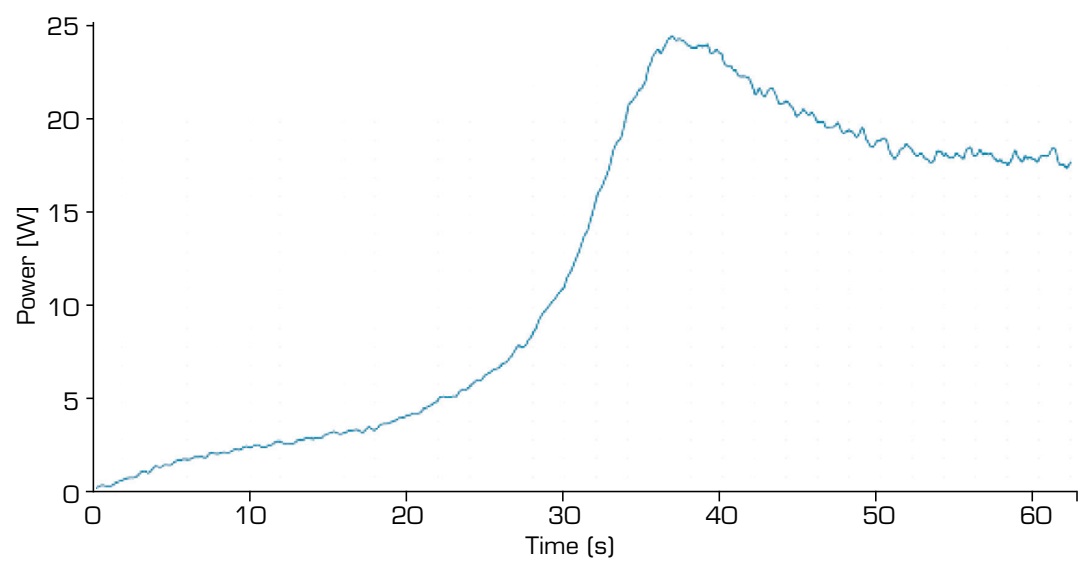

Figure 11. Time-series of the mechanical power produced by the three blades.

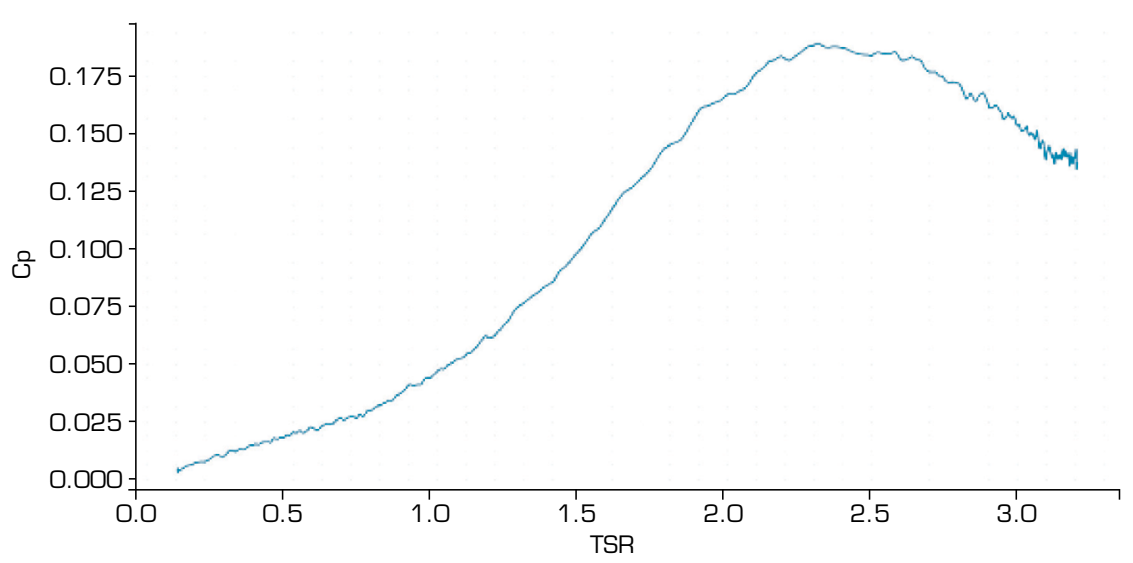

Figure 12. Power coefficient $(C p)$ vs. TSR for the three blades. 
For the five blades configuration, the average aerodynamic torque and angular speed, blade mechanical power, and $C p$ values are shown, respectively, in Figs. 13, 14, and 15.

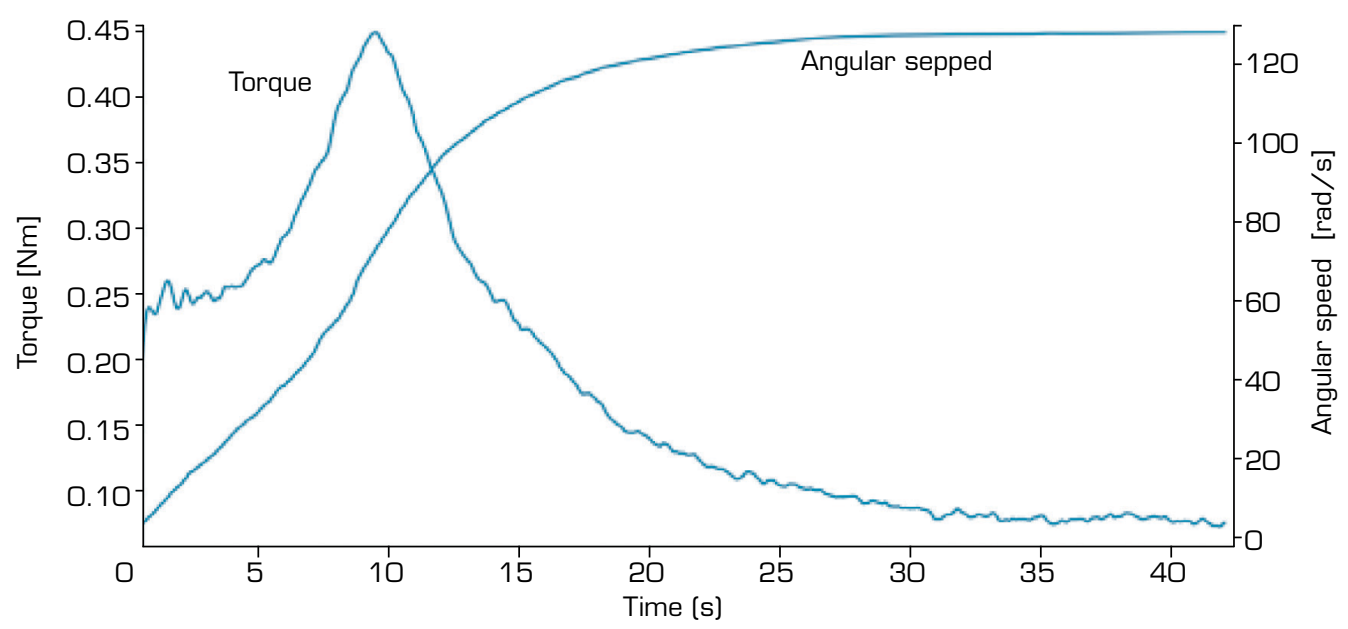

Figure 13. Time-series of the average aerodynamic torque and angular speed for the five blades.

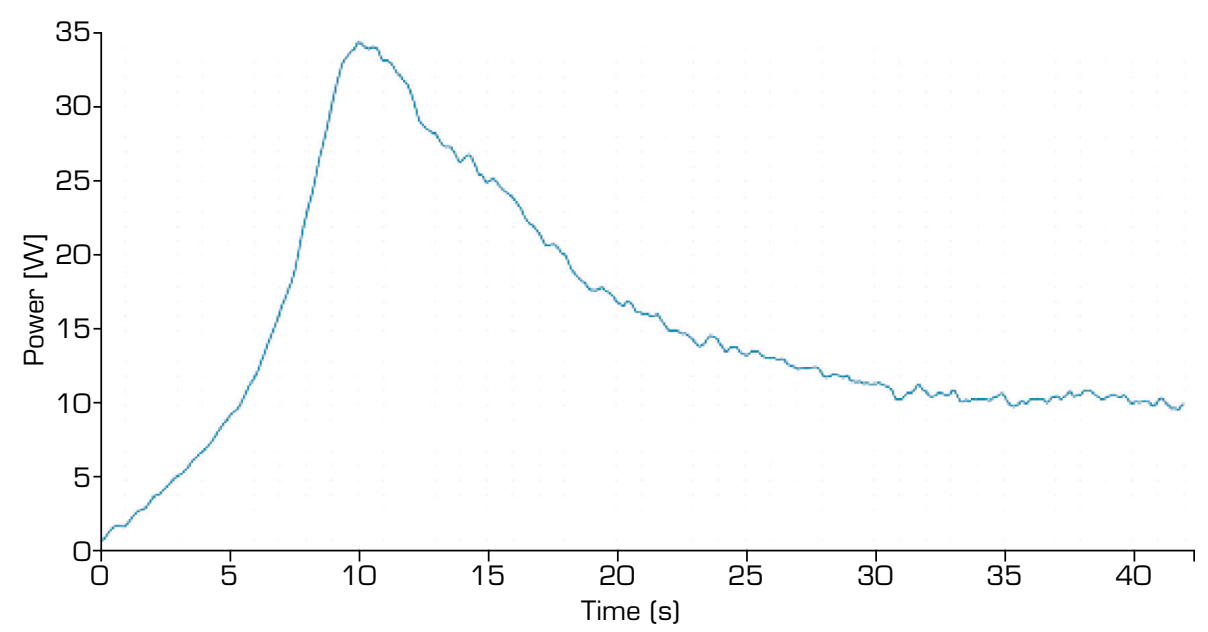

Figure 14. Time-series of the mechanical power produced by the five blades.

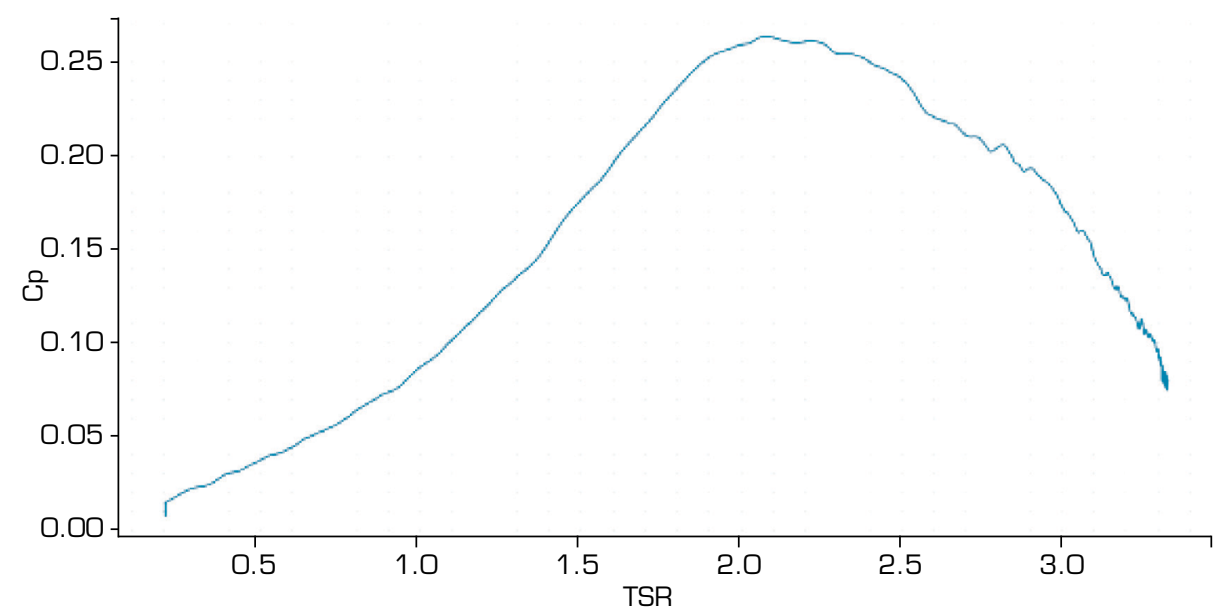

Figure 15. Power coefficient $(C p)$ vs. TSR for the five blades. 
The values of Eq. 3 are shown for the three and five blades, respectively, in Figs. 16 and 17. Subtracting the right side of the equation by the measured TQ value, in Eq. 3, the resultant must be zero. In the figures, one can see that up to the angular speed of $100 \mathrm{rad} \cdot \mathrm{s}^{-1}$, or $950 \mathrm{rpm}$, the values are on the range of $\pm 0.03 \mathrm{Nm}$. However, after this speed, the values decrease significantly, indicating that the equation outputs lose accuracy. This inaccuracy is because, in the spin-down tests, the resistive torques were calculated only until an angular speed in the range of $1000 \mathrm{rpm}$. Therefore, for speeds above $100 \mathrm{rad} \cdot \mathrm{s}^{-1}$, the resistive torques and, hence, the calculated aerodynamic torque are not accurate. However, the values of interest for the dynamic torque, acceleration, and power performance analyses occur before the erroneous angular speed.

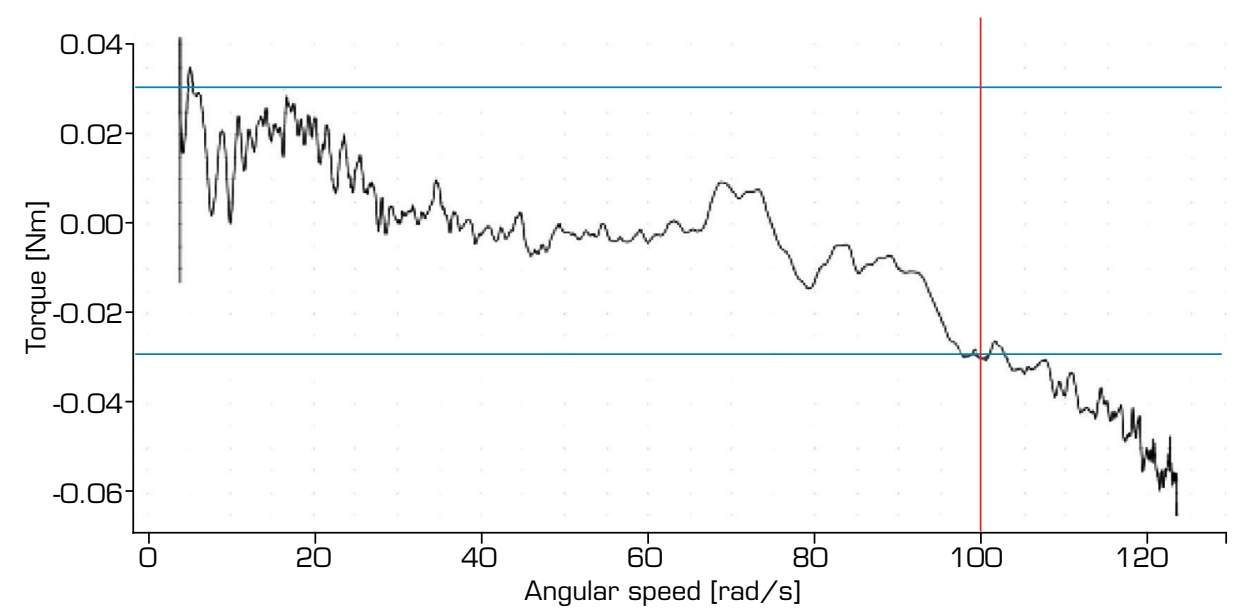

Figure 16. Equation 2 values for the three blades.

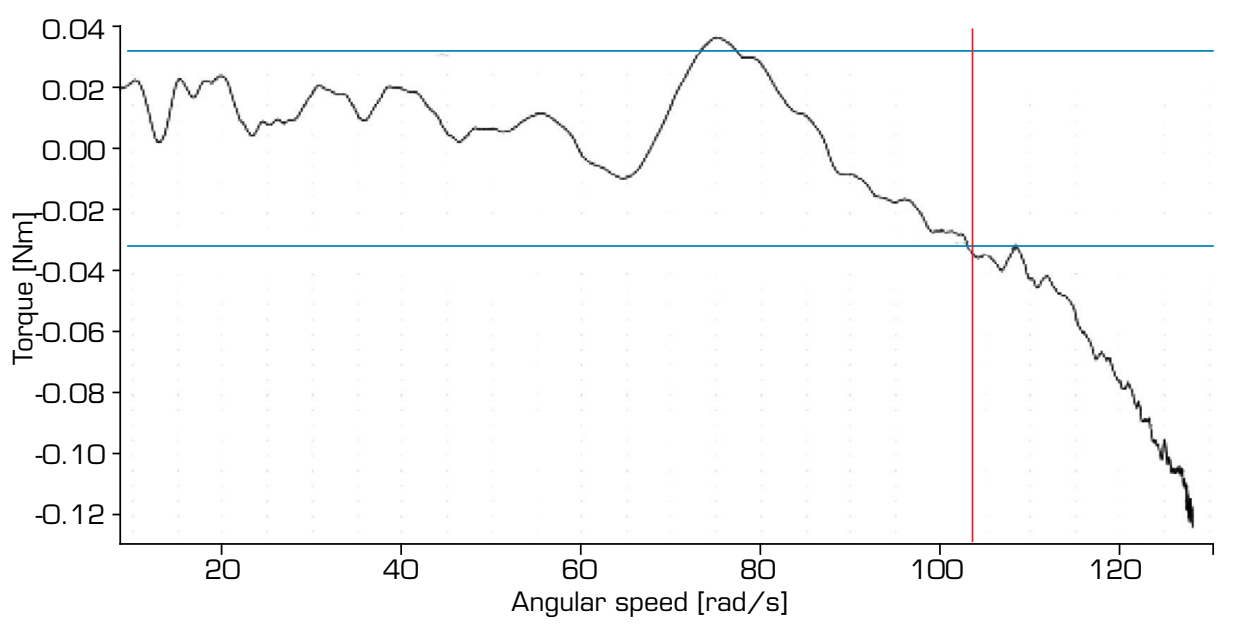

Figure 17. Equation 2 values for the five blades.

The noise, in the initial phase, of the aerodynamic torque curves (Figs. 10 and 13) was attributed to a relaxation of the torque meter shaft as the system was allowed to spin after being tensioned at the static part of the test (while the flow stabilized at the constant speed).

The main differences between the three and five blades configurations that can be pointed out are the static torque, starting time, and $C p$ values.

The five blades configuration had a $C p$ value $39 \%$ higher than the three blades, revealing a significant increase in power performance.

In this work, the starting time is defined as the time needed by the turbine to reach peak power. Its analysis is intricate, as it depends on factors such as the system mass moment of inertia and resistive torques. In most applications, the resistive torques have little dependence on the number of blades. Hence, blades addition will only affect the mass moment of inertia. 
In the present case, the increase in the system mass moment of inertia, related to the two blades, was $8 \%$. Therefore, the two extra blades inertia had minimum effect on the starting time. The three blades configuration starting time was 3.7 times higher than the five blades.

The difference in the starting times can be mainly attributed to the static torque values. The five blades configuration value was just below double the three blades. The low static torque of the latter resulted in a long idling time, in which the turbine spins but has minimal increase in its aerodynamic torque. The idling period of both assemblies persisted until they reached the angular speed of $30 \mathrm{rad} \cdot \mathrm{s}^{-1}$ or the tip-speed ratio of 0.78 . The five blades had a maximum aerodynamic torque value $40 \%$ higher than the three blades configuration. It should be mentioned that, for the three blades case, there was a gap between the blade base, which may have reduced its power performance, however this fact was considered to have a negligible impact.

Comparing the value added of mass moment of inertia when not considering the disc, the turbine had it increased by $50 \%$, as it is dominated by the blades. In these situations, the improvement of the starting time will be lower than the observed in this work and should be further investigated in a real operational system.

\section{CONCLUSIONS}

This work experimentally investigated the effects that a different number of blades have in a horizontal-axis SWT dynamic torque, acceleration, and power performance. It presented the methodology for calculating the temporal behavior of the aerodynamic torque produced by the blades during its acceleration phase. Wind tunnel tests were performed with three blades and five blades assembly configuration.

The measurements were conducted using an in-line dynamic torque meter, and the angular speed was acquired by a frequency domain analysis of the torque signal. The signal processing was performed by a National Instruments USB-6009 device. The torque meter signal was filtered using a 3rd order low-pass Butterworth digital filter.

The system was composed by the turbine, the torque meter, and an inertia disc. The resistive torques of the system were calculated by spin-down tests. The torque measured at the torque meter was used to calculate the aerodynamic torque of the blades by the use of the dynamic equation of the system. The measurements started at still and were finalized when the angular speed reached a constant value and the system had stabilized. The tests were performed at a wind speed of $10 \mathrm{~m} \cdot \mathrm{s}^{-1}$.

The manufacturing of the model parts by AM shows how this technology can be applied to improve and facilitate the design of SWT components.

The results showed that the addition of two blades increased the maximum $C p$ value of the turbine by $39 \%$ when compared to the three blades model. The five blades configuration also displayed a shorter starting time, mainly because of a static torque value about two times greater than the three blades. A mutual angular speed was identified as the transitional point between the idling period and fast acceleration periods of the models.

The data provided in this work can be used for the development of more accurate numerical models, as it presents dynamic response measurements, an intricate part of SWTs operation.

The relative simplicity and low-cost of SWTs blades manufacturing, combined with the significant gains in power performance and starting time show that SWTs can considerably benefit from a higher number of blades in their design.

\section{AUTHORS' CONTRIBUTION}

Conceptualization: Porto HA; Data Curation: Porto HA; Project Administration: Fortulan C; Porto AJV; Resources: Fortulan C; Porto AJV; Supervision: Fortulan C; Porto AJV; Formal Analysis: Porto HA; Fortulan C; Porto AJV; Investigation: Porto HA: Fortulan C; Porto AJV; Methodology: Porto HA; Writing - Original Draft Preparation: Porto HA; Writing - Review \& Editing: Porto HA; Fortulan C; Porto AJV. 


\section{DATA AVAILABILITY STATEMENT}

The data will be available upon request.

\section{FUNDING}

Conselho Nacional de Desenvolvimento Científico e Tecnológico

[https://doi.org/10.13039/501100003593]

\section{ACKNOWLEDGEMENTS}

Not applicable.

\section{REFERENCES}

Ani SO, Polinder H, Ferreira JA (2013) Comparison of energy yield of small wind turbines in low wind speed areas. IEEE Trans Sustain Energy 4(1):42-49. https://doi.org/10.1109/TSTE.2012.2197426

Clifton-Smith MJ, Wood DH (2007) Further dual purpose evolutionary optimization of small wind turbine blades. J Phys Conf Ser 75:012017. https://doi.org/10.1088/1742-6596/75/1/012017

Duquette MM, Visser KD (2003) Numerical implications of solidity and blade number on rotor performance of horizontalaxis wind turbines. J Sol Energy Eng 125(4):425-432. https://doi.org/10.1115/1.1629751

Fields J, Oteri F, Preus R, Baring-Gould I (2016) Deployment of wind turbines in the built environment: Risks, lessons, and recommended practices. National Renewable Energy Lab. (NREL), Golden, CO (United States). Report No.: NREL/TP-500065622. https://doi.org/10.2172/1260340

Grieser B, Sunak Y, Madlener R (2015) Economics of small wind turbines in urban settings: An empirical investigation for Germany. Renew Energ 78:334-350. https://doi.org/10.1016/j.renene.2015.01.008

Lovo JFP, Fortulan CA (2016) Estudo de propriedades mecânicas e anisotropia em peças fabricadas por manufatura aditiva tipo FDM. $1^{\circ}$ Simpósio do Programa de Pós-Graduação em Engenharia Mecânica EESC/USP-SiPGEM 2016. São Carlos, São Paulo, Brazil.

Lubitz WD (2014) Impact of ambient turbulence on performance of a small wind turbine. Renew Energ 61:69-73. https://doi. org/10.1016/j.renene.2012.08.015

Mithraratne N (2009) Roof-top wind turbines for microgeneration in urban houses in New Zealand. Energy Build 41(10):1013-1018. https://doi.org/10.1016/j.enbuild.2009.05.003

MK Controle e Instrumentação Ltda (2021) MKDQ. MK Controle e Instrumentação Ltda. [accessed Aug 28 2021]. http:// www.mkcontrole.com.br/torque/156-mkdq

National Instruments (2017) USB-6009 Specifications. National Instruments. [accessed Aug 28 2021]. http://www.ni.com/ pdf/manuals/375296c.pdf 
Olsen T, Preus R (2015) Small wind site assessment guidelines. National Renewable Energy Lab. (NREL), Golden, CO (United States). Report No.: NREL/TP-5000-63696. https://doi.org/10.2172/1225476

Peacock AD, Jenkins D, Ahadzi M, Berry A, Turan S (2008) Micro wind turbines in the UK domestic sector. Energy Build 40(7):1324-1333. https://doi.org/10.1016/j.enbuild.2007.12.004

Pourrajabian A, Ebrahimi R, Mirzaei M (2014) Applying micro scales of horizontal axis wind turbines for operation in low wind speed regions. Energy Convers Manag 87:119-127. https://doi.org/10.1016/j.enconman.2014.07.003

Pourrajabian A, Afshar PAN, Ahmadizadeh M, Wood D (2016) Aerostructural design and optimization of a small wind turbine blade. Renew Energ 87(Part 2):837-848. https://doi.org/10.1016/j.renene.2015.09.002

Scappatici L, Bartolini N, Castellani F, Astolfi D, Garinei A, Pennicchi M (2016) Optimizing the design of horizontalaxis small wind turbines: From the laboratory to market. J Wind Eng Ind Aerodyn 154:58-68. https://doi.org/10.1016/j. jweia.2016.04.006

Sessarego M, Wood D (2015) Multi-dimensional optimization of small wind turbine blades. Renewables 2:9. https://doi. org/10.1186/s40807-015-0009-x

Sunderland K, Woolmington T, Blackledge J, Conlon M (2013) Small wind turbines in turbulent (urban) environments: A consideration of normal and Weibull distributions for power prediction. J Wind Eng Ind Aerodyn 121:70-81. https://doi. org/10.1016/j.jweia.2013.08.001

Sunderland KM, Narayana M, Putrus G, Conlon MF, McDonald S (2016) The cost of energy associated with micro wind generation: International case studies of rural and urban installations. Energy 109:818-829. https://doi.org/10.1016/j. energy.2016.05.045

Tang C, Soong WL, Freere P, Pathmanathan M, Ertugrul N (2013) Dynamic wind turbine output power reduction under varying wind speed conditions due to inertia. Wind Energ 16:561-573. https://doi.org/10.1002/we.1507

Tummala A, Velamati RK, Sinha DK, Indraja V, Krishna VH (2016) A review on small scale wind turbines. Renew Sustain Energy Rev 56:1351-1371. https://doi.org/10.1016/j.rser.2015.12.027

van Kuik GAM, Sørensen JN, Okulov VL (2015) Rotor theories by Professor Joukowsky: Momentum theories. Prog Aerosp Sci 73:1-18. https://doi.org/10.1016/j.paerosci.2014.10.001

Wilson SVR, Clausen PD (2007) Aspects of the dynamic response of a small wind turbine blade in highly turbulent flow: Part 1 measured blade response. Wind Eng 31(1):1-16. https://doi.org/10.1260/030952407780811429

Wood DH (2004) Dual purpose design of small wind turbine blades. Wind Eng 28(5):511-527. https://doi. org/10.1260/0309524043028037

Wright AK, Wood DH (2004) The starting and low wind speed behaviour of a small horizontal axis wind turbine. J Wind Eng Ind Aerodyn 92(14-15):1265-1279. https://doi.org/10.1016/j.jweia.2004.08.003 